be used in food must rest on considerations other than those of its toxicity. Such considerations may be within the field of nutrition rather than the narrower limits of toxicology.

\title{
REFERENCES
}

Buttle, G. A. H. \& Dyer, F. J. (1950). Y. Pharm. Pharmacol. 2, 371.

Cook, J. W. (1948). Brit. \%. Nutrit. 1, 245.

Coppock, J. B. M. (r950). Y. Sci. Food Agric. 1, 125.

Deichmann, W. \& Witherup, S. (1942-3). F. Lab. clin. Med. 28, 1725.

Fitzhugh, O. G. (1948). Industr. Engng Chem. 40, 704.

Fitzhugh, O. G. \& Nelson, A. A. (1950). Fed. Proc. 9, 272.

Gavrilescu, N. \& Peters, R. A. (1931). Biochem. F. 25, 2 I 50.

Harris, R. S., Sherman, H. \& Jetter, W. W. (1950). Fed. Proc. 9, $36 \mathrm{r}$.

Kirby, A. H. M. \& Peacock, P. R. (1949). Glasgow med. J. 30, 364.

Krantz, T. C. Jr., Carr, C. J., Bird, J. G. \& Cook, S. (1948). J. Pharmacol. 93, 188.

Laug, E. P., Nelson, A. A., Fitzhugh, O. G. \& Kunze, F. M. (1950). Y. Pharmacol. 98, 268.

Laug, E. P., Prickett, C. S. \& Kunze, F. M. (1950). Fed. Proc. 9, 294.

Machle, W., Heyroth, F. F. \& Witherup, S. (1944). F. biol. Chem. 153, 551.

Rhodes, A., Sexton, W. A., Spencer, L. G. \& Templeman, W. G. (1950). Research, 3 , 189.

Schweigert, B. S., McBride, B. H. \& Carlson, A. J. (1950). Proc. Soc. exp. Biol., N. Y., $73,427$.

Shaffer, C. B., Critchfield, F. H. \& Carpenter, C. P. (1948). Amer. F. Physiol. 152, 93.

Shaffer, C. B., Critchfield, F. H. \& Nair, J. H. III. (1950). F. Amer. pharm. Ass. 39, 340.

Smyth, H. F. Jr., Carpenter, C. P., Shaffer, C. B., Seaton, J. \& Fischer, L. (1942). J. industr. Hyg. 24,281 .

Smyth, H. F. Jr., Carpenter, C. P. \& Weil, C. S. (1950). F. Amer. pharm. Ass. 39, 349.

Tainter, M. L. (1943). Proc. Soc. exp. Biol., N.Y., 54, 77.

Tauber, O. E. \& Hughes, A. B. (1950). Proc. Soc. exp. Biol., N.Y., 75, 420.

Wang, H., McBride, B. H. \& Schweigert, B. S. (r950). Proc. Soc. exp. Biol., N. Y., 75, 342.

\section{Chemical Additives and Adulterants in Food}

\section{By J. B. M. Coppock, Baking Industries Research Association, Chorleywood, Herts}

\section{Introductory}

The question which it is proposed to discuss is one closely linked with the use of chemical additives in foodstuffs and with the potential adulteration resulting from the use of processing and hygiene aids. It is the evaluation of the functional value of chemicals, which may be suggested for these three methods of use, that will be particularly considered. Thus, only if it can be demonstrated that a chemical has a significant practical effect, i.e. a real functional value, for the purpose proposed does it become necessary to study its pharmacology in relation to the conditions of use suggested.

The discovery of an increasing number of new chemical substances has resulted in the exploration of numerous fields for their use, including the food industry, which finds itself faced with the potential use of chemicals for many purposes, some of which are outlined in Table $\mathrm{r}$. Whatever the particular use of each of these materials may be, there is the possibility that human beings may ingest them in large or small amounts, either by their deliberate inclusion as food additives, or as residues from their use at some stage in food production.

It is clear, therefore, why some of us who have become intimately acquainted with the problem have urged the necessity for precise knowledge of the pharmacology of 
Table I. Suggested uses for various chemical substances in processes of food production

\begin{tabular}{|c|c|c|}
\hline Substance & Suggested use & Group \\
\hline $\begin{array}{l}\text { Methyl cellulose and other } \\
\text { cellulose derivatives }\end{array}$ & Emulsification agent & Additive \\
\hline Butylated hydroxyanisole & Anti-oxidant & Additive \\
\hline $\begin{array}{l}\text { 'Glyccryl monostearate' containing } \\
\text { mono-, di- and tri-esters }\end{array}$ & Crumb-softening agent in bread & Additive \\
\hline Ascorbic acid & Flour improver & Additive \\
\hline Propoxynitraniline (P 4000$)$ & Sweetening agent & Additive \\
\hline Alkyl and aryl silicones & $\begin{array}{l}\text { Thermostable pan glaze in bread } \\
\text { production }\end{array}$ & Process aid \\
\hline Mineral oil & $\begin{array}{l}\text { Lubricant for machines used } \\
\text { in food production }\end{array}$ & Process aid \\
\hline 'Tetrachloronitrobenzene & $\begin{array}{l}\text { Agent to arrest sprouting of } \\
\text { potatoes in clamp }\end{array}$ & $\begin{array}{l}\text { Preservation of } \\
\text { agricultural produce }\end{array}$ \\
\hline DDT & Insecticide & Hygiene aid \\
\hline Quaternary ammonium compounds & Detergent and bactericide & Hygiene aid \\
\hline Ethyl mercuric phosphate & Fungicide & $\begin{array}{l}\text { Preservation of } \\
\text { agricultural produce }\end{array}$ \\
\hline
\end{tabular}

chemical food additives and adulterants, particularly their long-term chronic effects and also the effect they may have on nutrition.

In a paper read to the Society of Chemical Industry it was suggested that the pharmacologist, the chemist, the nutritionist, the clinician and the food scientist ought to have some opportunity for discussing and exploring together the problems involved in the potential introduction of new substances in food manufacture (Coppock, 1950). The health of the community may be affected by the use of chemicals as additives, and as technological and hygiene aids in food production and in the protection and preservation of crops, so that mutual exchange of information is vital. It was further suggested that the discussion of the problems which might arise ought not to be hasty, but should be conducted in an atmosphere of calm scientific approach free from all bias. For example, in America the use of certain antioxidants that reduce fat spoilage is permitted, and in considering whether their use should be permitted also in this country, it is necessary to consider their possible toxicity on the one hand and relate it to the potential carcinogenic and other effects that may be associated with the development of oxidative rancidity in heated fats; evidence for such effects has been obtained by Peacock \& Beck (1948) in animal experiments with certain fats in which the process of heating can be likened to the production of accelerated rancidity.

\section{Need for national consultative organization}

The problem confronting all of us who are dealing with the science of food is one of great magnitude, and it was suggested that a national organization was necessary to co-ordinate and study its many ramifications. Guidance is required on the type and extent of the pharmacological data necessary to decide whether a substance is harmless or not. It is clear that in any system of pharmacological testing the food scientist will be required to state the potential use to which a new substance might be put, 
and it will be necessary to know the concentrations likely to be used and to relate them to the scheme of testing. It appears, therefore, that many problems will require individual investigation, and broad generalizations based on the normal type of toxicological screening will rarely be sufficiently precise except as a means of preliminary sorting. Frazer (195I) has reviewed recently some of the problems inherent in the pharmacological approach which involve in many cases studies of absorption, metabolism and acute and chronic toxicity. It is probable that radioactive tracers will play an increasingly large part in the detection of contamination by new technological aids, and in the study of ingestion and of accumulation in the main viscera, more particularly where the quantities of chemicals used in foods are only small. The chemist too will be required to play his part in elaborating standards of chemical purity, in developing processes for the production of materials conforming with the required standards, and in devising adequate methods of quantitative analysis, particularly of inorganic and organic residues resulting from the use of technological aids.

It will be readily appreciated that a programme of this type, envisaging a large national organization, is not in the foreseeable future a financial possibility. Indeed, on reflexion, it appears wrong that public money should be expended in testing a large number of new substances, of which only a small number might ultimately find their way into our food. Some people may be tempted to say that because of these difficulties the use of chemicals should be completely banned. This, in the author's view, would be a wrong decision in view of the advantages that certain substances possess, and it might give rise to long discussions on such matters as the use of baking powder or the relative merits of natural and synthetic vitainins.

It is now the considered opinion of the author that two forms of initial screening can be used which would reduce to reasonable proportions the pharmacological and other work necessary to prove that the use of a chemical substance for a specifically defined purpose was free from the risk of rendering a food injurious to health. The first screening would be the simple toxicological screening referred to earlier as by itself inadequate, and it would be related to the proposed use; it would define the degree of potential acute toxicity and, depending on the nature of this finding, the degree of chronic toxicity over a defined period, say 3 months. 'The second form of screening would be a precise assessment of the functional value, and only if this assessment was reasonably substantiated as with, for instance, already mentioned antioxidants, would the third stage of long-term toxicity tests and studies of the effect on nutrition be undertaken. I believe that in these circumstances the pharmacological and nutritional facilities required would not be much greater than those we already possess in our universities and other research organizations. It is when this stage has been reached that some national consultative committee should consider the available evidence and express an opinion on the desirability or otherwise of permitting the use of some new chemical substance in food production and, should the committee require additional evidence, expenditure of public money to obtain it would appear well justified. The importance that proof of practical usefulness has in the suggested scheme will, however, be appreciated and, though such a scheme may involve the devising of 
physical instruments capable of measuring selected organoleptic properties, and the development of other techniques involving the basic sciences, it is not beyond the capacity of food-research organizations successfully to carry it out.

\section{Examples illustrating the problems that arise}

'Three examples will illustrate the thesis. The first deals with a processing aid in which the analytical chemist is able to demonstrate that its use for the purpose specified is without hazard. The second concerns a food additive whose functional value has been clearly demonstrated by the use of physical instruments designed to measure selected organoleptic properties. The third has been selected to show how a microbiological technique may be used in examining the efficiency of a bactericide possessing at the same time the properties of a detergent which is under examination as a potential hygiene aid.

\section{Examination of a processing aid}

The alkyl and aryl silicones which are complex molecules of the type<smiles>[R][Si]([R])([R])O[Si]([R])([R])[C@H]1C[C@@H]([Si]([R])([R])[R])O1</smiles>

possess a clear-cut use in bread baking. There are still several technical difficulties that restrict their use, but they have real merit in eliminating the use of edible or mineral oils for greasing the baking tin. They are capable of producing on a baking tin a thin durable glaze of synthetic resin which can withstand repeated use for about 200 times without renewal. Previous evidence had indicated that these materials had a low degree of toxicity (Kerr, Anderson \& Harris, 1949; Rowe, Spencer \& Bass, I 948). In a series of comparative colorimetric determinations by the reaction between silicomolybdate and (a) stannous chloride, and $(b)$ benzidine, it was shown that there was no significant difference between the silicon content of bread baked in silicone-treated tins and in tins greased in the conventional manner (Coppock, Hulse \& Urie, 1949). The method used was a comparative one, since flour itself contains small amounts of combined silicon, c. $0.5 \mathrm{mg}$. Si/100 g. flour expressed on a dry basis, i.e. about 5 p.p.m. (Amos, private communication). In addition, determinations of the loss in weight from a silicone film during a series of baking experiments indicated that the maximum amount of silicone which could find its way into a loaf was $0.00005 \%$. It is, therefore, clear that without further toxicological information, the analytical chemist could obtain sufficient evidence that silicone pan-glaze can be used in bread production without hazard to the consumer.

The analytical data just mentioned were obtained by the British Baking Industries Research Association as part of a long-term programme of which the aim was to establish the harmlessness of various chemical additives and technological or hygiene aids that might be used in the baking industry and that might, to varying degrees, be consumed by human beings. 'This programme covers only a part of the whole field of 
food manufacture but it has made clear to the author the need for research work of the type mentioned, and for the establishment of an official and impartial advisory committee to examine and discuss critically results of the kind that has been quoted. This aspect of the matter appears to have been considered by a recent joint committee of the Society of Public Analysts and the Food Group of the Society of Chemical Industry. In a memorandum just published, they recommended, in reference to food additives, that 'a policy should be formulated with regard to such usages, giving a list of substances permitted for these purposes' (Society of Chemical Industry and The Society of Public Analysts and other Analytical Chemists: Joint Committee on Preservative Regulations, 1951). It is most important that food manufacturers as a whole should know what substances are suitable, i.e. deemed free from health hazard, for none of them would knowingly use any chemical material as an additive or as a technological or hygiene aid if the use involved a potential danger to public health; indeed Section I, I. $a$ of the Food and Drugs Act (1938) defines just this position without creating any machinery to advise on the problem or assist in carrying out the provisions of the Act.

\section{Examination of a food additive}

Health considerations are involved in any form of investigation into the problem of retaining crumb softness in bread. There are many reasons for research on this problem, such as the desire of the public to buy bread that will keep fresh, the desire of the baker to produce a uniformly attractive loaf, and factors connected with production which may be associated with the changing conditions in which we live. The last set of factors is often overlooked by those who designate as sophistication the inclusion of chemical substances in food for whatever purpose, and who disregard factors that are often beyond the manufacturer's control, but which may well affect his practice. Among the substances which have been examined in America and in this country for their effect on crumb texture are lecithin, glyceryl stearates and oleates, polyglyceryl esters, polyoxyethylene stearates, sorbitan esters of fatty acids and polyoxyethylene sorbitan esters. The pharmacological properties of many of these substances have been reviewed recently in America (Lehman, 1950), and caution has been advised in the use of the three last named; not so much because of what is at present known of their pharmacology and biochemistry, as because of the gaps in information. In the proposed new American bread standards (Thurston, 1950), lecithin and the mono- and diglycerides of fat-forming fatty acids are the only ones regarded as permissible and, in each instance for reasons which would appear peculiar to America, only in association with the shortening or fat used in American bread. American bread often contains up to $6 \%$ of fat so that the suggested inclusion of not more than $25 \%$ glyceryl monostearate in the shortening may lead to as much as $1.5 \%$ of it being present in the bread. This amount is considerably more than the $0.3 \%$ which produces the optimum degree of crumb softening in British bread, for which statement the evidence will be given later.

The author, with $\mathrm{Mr}$ M. A. Cookson, made a particular study of the effect of glyceryl monostearate in bread of the British type. The natural presence of this 
material in the bowel (Frazer, Schulman \& Stewart, 1944-5), as well as the pharmacological evidence, suggest that there is little reason to expect any adverse effect on the human system. Glyceryl monostearate, as at present used, is a mixture of the mono-, di- and tristearate, the monostearate portion being usually less than $50 \%$ of the whole. It is, therefore, closely related to natural fat and the mechanism of absorption is probably a similar one. For studying the functional value of glyceryl monostearate, instruments were constructed which could measure its effect on loaf volume, and on selected organoleptic properties that could be measured physically; such properties were firmness in relation to softness, crumb toughness in relation to chewing properties, and crumb stickiness (Cornford \& Coppock, 1950).

A series of experiments was performed with a standard baking technique in which control loaves were prepared according to a basic formula, containing flour, salt, yeast and water only, and were compared with other loaves containing in addition differing amounts of a self-emulsifying glyceryl monostearate which was added as a $17 \% \mathrm{w} / \mathrm{v}$ emulsion in water, the amount of water in the emulsion being deducted from the total amount used in preparing the dough. A comparison of loaves containing $0,0.05,0.1,0.2,0.3,0.5$ and $0.7 \%$ of glyceryl monostearate expressed as percentage of the flour weight indicated that the best type of loaf was one containing about $0.3 \%$. The results were confirmed more precisely with the instruments mentioned and by means of other tests such as slicing experiments. Table 2 illustrates the type of results obtained and compares the effect of two preparations of glyceryl monostearate, one containing $34 \%$ monoglyceride and $5 \%$ sodium stearate (which confers the property of self-emulsification), and another recently marketed in America containing $90 \%$ monoglyceride and $5 \%$ sodium stearate. The influence on loaf volume is clear and the effect on crumb softness is equally evident on reference to Fig. I, which compares the rate of hardening of control loaves containing no glyceryl monostearate with that of those containing the optimum concentration of $0.3 \%$, the materials used having the composition given above. In the same way, it is possible to determine the amounts of fat or of mixtures of fat and glyceryl monostearate which produce the optimum effect on crumb texture.

Table 2. Comparison of the effects of two preparations of glyceryl monostearate on certain properties of bread

\begin{tabular}{|c|c|c|c|c|}
\hline \multirow[b]{2}{*}{$\begin{array}{c}\text { Type of } \\
\text { monostearate } \\
\text { preparation }\end{array}$} & \multicolumn{2}{|c|}{ Volume of loaf } & & \\
\hline & $\begin{array}{l}\text { Control } \\
\text { loaf with no } \\
\text { addition } \\
\text { (ml.) }\end{array}$ & $\begin{array}{c}\text { Test loaf } \\
\text { with added } \\
\text { monostearate } \\
\text { (ml.) }\end{array}$ & Toughness & Stickiness \\
\hline $\begin{array}{l}\text { Monoglyceride } 34 \% \\
\text { sodium stearate } 5 \%\end{array}$ & $135^{8}$ & $1490)$ & & \\
\hline $\begin{array}{l}\text { Monoglyceride } 90 \%, \\
\text { sodium stearate } 5 \%\end{array}$ & $135^{8}$ & 1462 & & l More sticky \\
\hline
\end{tabular}

In another investigation the author, with Miss $\mathrm{R}$. Bennett, has shown recently that glyceryl monostearate has a pronounced effect on the improving action of vitamin $\mathrm{C}$ on flour. A mixture of the two substances appeared to have a synergistic action, so that 
the bread made with the mixture was superior to that obtained with either material alone, even when the amount used was somewhat less than half the optimum amount for either substance alone. Similar results were also obtained with combinations of fat and ascorbic acid, as little as ro p.p.m. of the latter being effective with a 3-4 hr. period for fermentation of the dough. The interesting speculation then arises whether the composition of the diet might not have similar effects, and suggests that there is yet much to learn about the influence of the gastric contents, in the presence and absence of food additives, on the specific absorption of dietary essentials.

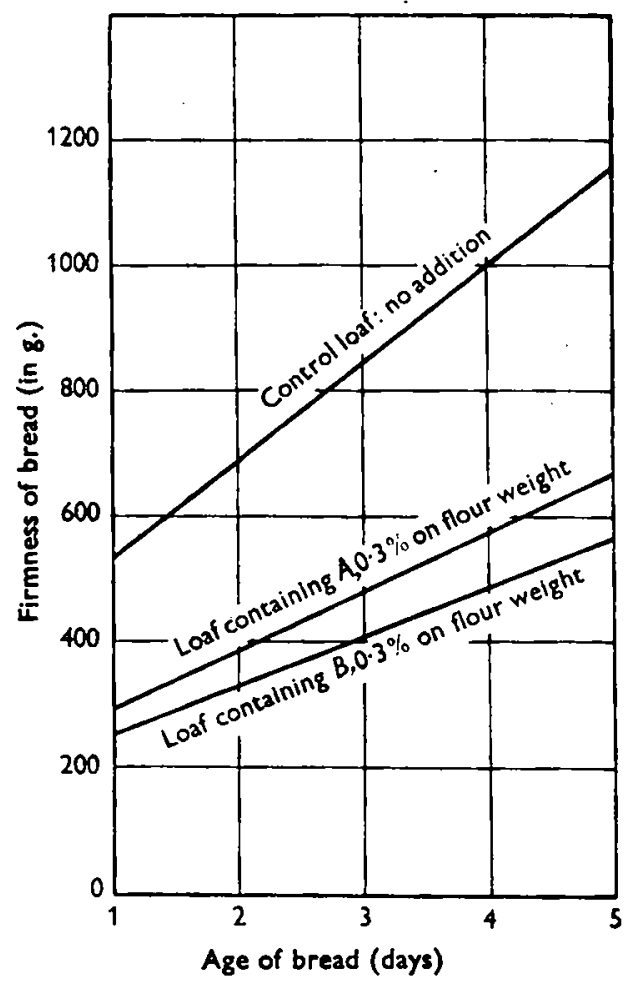

Fig. I. Effect of two preparations of glyceryl 'monostearate', one, $A$, containing $34 \%$ of monoglyceride and $5 \%$ of sodium stearate, and the other, $B$, containing $90 \%$ of monoglyceride and $5 \%$ of sodium stearate, on the firmness of bread, expressed in $\mathrm{g}$. and determined by compressing a disk of crumb $3.2 \mathrm{~cm}$. in diameter and $8.02 \mathrm{sq} . \mathrm{cm}$. in area to half its original thickness.

It will be apparent from these examples that it is possible to design experiments to provide precise information on the functional value of food additives. The pattern of this type of research is not different from that in any other form of scientific inquiry but is usually complicated by the very large number of the variables that are involved in the preparation and constitution of a food. It would of course be unprofitable to embark on a research of this scope had the initial toxicological evidence not suggested that the substance under investigation appeared to be safe for human consumption. Probably with glyceryl monostearate the wealth of information available from America makes it unnecessary to seek for further data, but the food manufacturer would feel in 
a stronger position if some committee had reviewed the evidence and had agreed that the substance was a satisfactory component of food, for its use is not limited only to bread.

\section{Application of a microbiological technique to the examination of a bactericidal and deter- gent substance}

The third illustration has been chosen as an example of where, in the author's view, real uncertainty and doubt exist about the conditions in which it is safe to use the quaternary ammonium compounds as detergents or bactericides or as both, for which purposes they would appear to have a real functional value. Lehman (1950) regards these cationic wetting agents as possessing in general a high degree of toxicity and considers them as poisons so that their use in food cannot be justified. It is clear that their use as hygiene aids places them within the fringe of this adverse view. Fitzhugh \& Nelson (1950) have demonstrated small foci of haemorrhagic necrosis in the gastric mucosa of rats ingesting $0.063 \%$ of an alkyl-dimethyl-benzyl ammonium chloride in the diet for a period of 2 years. With Mrs D. E. Cookson, the author has recently found that cetyl-trimethyl-pyridinium bromide and the corresponding ammonium bromide lyse blood and that they are only partially removed from glass and other surfaces by rinsing (Coppock, 1950). The capacity to lyse blood is retained in acid media, and is not at all readily lost since the same effect was obtained after twelve rinses, commencing with a solution of the quaternary ammoniun compound at a dilution of $I$ in 10,000 .

More recently a study has been made of the effect of milk and egg solids on the bactericidal properties of these compounds. In one series of experiments a suspension of Staphylococcus pyogenes was prepared and divided into three equal parts, to each of which cetyl-trimethyl-ammonium bromide was added, the final concentration being $I$ in 5000 ; to one part no further addition was made, to the second was added $\mathrm{x} \%$ of milk solids, and to the third I \% of egg solids. Samples were planted at appropriate intervals on to $7 \%$ salt agar, and counts of the bacteria present were subsequently made. 'The results are set out in Table 3 . They show the inhibitory effect of the milk

Table 3. Effect of a quaternary ammonium compound on Staphylococcus pyogenes in the presence of milk or egg solids. Initial concentration 200,000 organisms/g. Temperature $\mathrm{I}^{\circ}$

$\begin{array}{cccc} & \text { No. of organisms in presence of cetyl-trimethyl-ammonium bromide } \\ \text { Time } & & \text { With I \% } & \text { With I \% } \\ \text { (min.) } & \text { Alone } & \text { milk solids } & \text { egg solids } \\ \text { I } & 10,700 & \text { Uncountable } & 242,400 \\ \text { II } & 3,728 & \text { Uncountable } & 314,700 \\ 21 & 3,700 & \text { Uncountable } & 356,800 \\ 31 & - & \text { Uncountable } & \mathbf{8 2 1 , 6 0 0} \\ 6 \text { 6I } & 680 & \text { Uncountable } & \text { Uncountable } \\ 91 & - & \text { Uncountable } & \text { Uncountable }\end{array}$

and egg solids on the bactericidal action of a dilute solution of cetyl-trimethylammonium bromide. A similar inhibition of bactericidal properties is caused by 
fats. It would appear, therefore, that in the same way the gastric contents may be capable of inactivating quaternary ammonium compounds in low concentrations and that, contrary to our earlier belief (Coppock, 1950), the potential risk of blood lysis involved in their use may be very small. It may well be, however, that, since higher concentrations of quaternary ammonium compounds are effective bactericides, there might be a temptation to increase the concentration, which might lead to the contamination of food brought into contact with surfaces treated in this way. Quantities far in excess of $\mathrm{I}$ or $\mathbf{2}$ p.p.m. might thus be introduced into food. It would be unwise, therefore, to recommend these materials for general use in the food industry until further knowledge of their properties is available, although their use at low concentrations of about $I$ in 6500 for specific purposes such as rinsing beer glasses might be regarded as an exception. Results of this type further emphasize the need for a consultative committee, having this sort of information at their disposal, or having fostered facilities for obtaining it, and able, therefore, to advise generally and specifically on the safety of procedures of this type.

\section{Conclusion}

There are many further examples that could be quoted to justify the need for guidance. Sometimes it might be necessary to recommend precautions beyond those legally defined, as for instance in the advice (Coppock \& Cookson, 1949) given to the baking industry about the purity of the mineral oil to be used for lubrication for which no specification is made in the Mineral Oil in Food Order 1949 (S.I. 614), where the weight of mineral oil permitted in food resulting from processing operations is given as $0.2 \%$. After consultation with Professor Frazer it was felt that mineral oils of high viscosity were less likely to be absorbed and possibly cause liver damage than oils of low viscosity, so that a recommendation was made that the chemical purity of mineral oil likely to come in contact with food during baking should be not less than that of liquid paraffin B.P. This example emphasizes the need for some consultative committee to examine carefully the potential uses of the substances brought to its notice, and suggests that the constitution of the committee should be wide enough to enable it to obtain the necessary evidence from the representatives of industry.

There can, in the author's opinion, be little doubt that an advisory committee of the type suggested is necessary in view of the problems revealed by this examination of some of the difficulties facing the food scientist. The problems arise not only as a consequence of the new substances that the chemical industry puts forward as likely to be useful, but also because new trends in hygiene, in modes of transport, in food preservation, in crop protection, and in packing and production yield an increasing number of instances where guidance is an urgent necessity.

The work of a consultative committee would at first be heavy because of the accumulation of problems requiring an answer, but it is the author's view that in the future many materials would be eliminated by a preliminary pharmacological screening, followed by evidence of a real practical application or functional value. The total amount of additional pharmacological and nutritional research would not then become unwieldy, and the possibility of giving helpful advice to the food producer 
would be realized within rational and economic limits. Such an arrangement clearly requires the co-operation of the food producers and the food research organizations with the Ministries of Food, Health and Agriculture and, almost certainly, at some stage in the third phase of inquiry, guidance by the Medical Research Council on the need and pattern of further research.

\title{
REFERENCES
}

Coppock, J. B. M. (1950). Y. Sci. Food Agric. I, 349.

Coppock, J. B. M. \& Cookson, M. A. (1949). F. Soc. chem. Ind., Lond., 68, 274.

Coppock, J. B. M., Hulse, H. \& Urie, A. (1949). Brit. med. Y. ii, 597.

Cornford, S. J. \& Coppock, J. B. M. (1950). Research, 3, 558.

Fitzhugh, O. G. \& Nelson, A. A. (1950). Fed. Proc. 9, 272.

Frazer, A. C. (1951). Y. Sci. Food. Agric. 2, r.

Frazer, A. C., Schulman, J. H. \& Stewart, H. C. (1944-5). J. Physiol. ro3, 306.

Kerr, S. R., Anderson, R. C. \& Harris, P. N. (r949). I. Amer. pharm. Ass. (Sci. ed.), 38, 38.

Lehman, A. J. (1950). Bull. Ass. Food and Drug Officials, 14, no. 3, p. 82.

Peacock, P. R. \& Beck, S. (1948). Nature, Lond., 162, 252.

Rowe, V. K., Spencer, H. C. \& Bass, S. L. (1948). F. industr. Hyg. 30, 332.

Society of Chemical Industry and The Society of Public Analysts and other Analytical Chemists: Joint . Committee on Preservative Regulations (195I). Chem $\mathscr{O}^{\circ}$ Ind. p. I4I.

Thurston, J. L. (1950). Federal Register, 15, 5102.

SIXTY-SEVENTH SCIENTIFIC MEETING-THIRTY-FIRST

SCOTTISH MEETING

HANNAH DAIRY RESEARCH INSTITUTE, KIRKHILL, AYR

2I APRIL 195I

\section{MILK}

Chairman: PROFESSOR R. C. GARRY, Institute of Physiology, University of Glasgow

\section{Trends in Milk Consumption in Great Britain}

\author{
By Dorothy F. Hollingsworth, Scientific Adviser's Division, Ministry of Food, \\ Great Westminster House, Horseferry Road, London, S.W. I
}

This Society last devoted a whole day to milk in July I 943 at a joint meeting with the Food Group of the Society of Chemical Industry. In the first paper at that meeting Mr J. L. Davies (1944), of the Milk Marketing Board, discussed the changes in the supplies of liquid milk which had occurred between 1933 and 1943 and posed a number of questions. Among these were: What should be the rate of liquid milk consumption to meet a progressive nutritional policy? How much milk would people buy when other foods become plentiful again? Would supplies be sufficient to meet the high nutritional requirements he postulated?

Data collected during the 8 years since that meeting suggest some answers to these questions. It is proposed here to discuss some of these data. 